\title{
Giardia lamblia infection in homosexual men
}

\author{
JOEL D. MEYERS, HENRY A. KUHARIC, AND KING K. HOLMES \\ From the Department of Medicine, United States Public Health Service Hospital and the Department of \\ Medicine, University of Washington, School of Medicine, Seattle, Washington 98195, USA
}

SUMMARY Epidemic Giardia lamblia infection has usually been associated with contaminated water. In this paper, five proved and one presumed case of $G$. lamblia infection among homosexual men are reported. The sequential onset of their clinical illnesses and their sexual interrelationships suggest that this outbreak could have been caused by the direct faecal-oral transmission of G. lamblia. Other parasitic diseases with possible venereal transmission have been described, and parasitic diseases should be considered in homosexual men with diarrhoea or other gastrointestinal symptomatology.

\section{Introduction}

Giardia lamblia infection is ubiquitous. Twenty-four stool surveys conducted in the United States of America before 1948 revealed a combined prevalence rate of G. lamblia cysts of 7.4\%, compared with $6.9 \%$ in 20 surveys throughout the rest of the world (Belding, 1952). At the present time G. lamblia infection is apparently less common in Seattle, Washington; cysts were detected in stool samples of only 18 of 590 patients $(3.1 \%)$ examined at the US Public Health Service Hospital during 1974-75 (mean 1.7 specimens/patient), four of whom are patients presented here. Epidemic $G$. lamblia has generally been associated with contaminated water supplies (Moore et al., 1969; Brodsky et al., 1974) although direct faecal-oral transmission is clearly possible. This paper reports the successive occurrence of symptomatic $\boldsymbol{G}$. lamblia infection in a group of homosexual men and suggests that faecal-oral transmission may have been responsible for this outbreak.

\section{Clinical histories and epidemiology}

Patient A first sought medical attention for recurrent diarrhoea on 31 July 1975 . He had had remitting diarrhoea without fever or abdominal cramps since the beginning of 1975 , with persistent diarrhoea for

This research was supported by the National Institute of Allergy and Infectious Diseases Training Grant AI00191-02.

Address for reprints: Joel D. Meyers, MD, Division of Infectious Diseases, US Public Health Service Hospital, 1131 14th Avenue South, Seattle, Washington 98114, USA

Received for publication 4 August 1976 the month preceding the visit. There was no known exposure to persons with diarrhoeal illness or to contaminated water supplies. A stool specimen obtained one week before the initial visit contained Iodamoeba butschlii and Endolimax nana cysts as well as G. lamblia. He was treated with metronidazole with resolution of symptoms and a single negative stool on 8 August. He declined subsequent examinations.

Patient B noted the onset of frequent, soft, lightcoloured, floating stools during the first week of July. He first sought medical attention on 15 August, after a weight loss of $1.5 \mathrm{~kg}$; a stool was positive for G. lamblia cysts. Exposure history included a hiking trip on 30 June during which he drank from several mountain streams. He lived with and was a sexual partner of Patient A (Table). Symptoms resolved on metronidazole, and he declined additional examinations.

On 14 July Patient $C$ had the onset of nausea, anorexia, and watery, floating stools. A stool sample obtained on 15 August was positive for G. lamblia cysts; he improved on metronidazole treatment and declined further examinations. He had no known exposure to contaminated water, but was a sexual partner of Patient A and lived with Patients A, B, and $F$ (Table). His most recent sexual encounter with Patient $\mathrm{A}$ before the onset of symptoms had been between eight and ten days previously.

Patient D had the onset of symptoms on 25 July; he had no known exposure to contaminated water. Stool samples were positive for G. lamblia on 16 and 18 August, and were subsequently negative on four occasions after metronidazole treatment, although diarrhoea continued intermittently. Patient $\mathbf{D}$ did not live with any of the preceding patients, but had 
Table Onset of clinical symptoms, date of stool samples positive for $\mathrm{G}$. lamblia, and number of sexual contacts who were infected with $\mathrm{G}$. lamblia

\begin{tabular}{|c|c|c|c|c|}
\hline Patient & $\begin{array}{l}\text { Date of } \\
\text { onset of } \\
\text { symptoms }\end{array}$ & $\begin{array}{l}\text { Date of } \\
\text { first positive } \\
\text { stool }\end{array}$ & $\begin{array}{l}\text { Sexual } \\
\text { contacts with } \\
\text { G. lamblia } \\
\text { infection }\end{array}$ & Sexual contact \\
\hline$A^{*}$ & $30 / 6$ & $24 / 7$ & $\mathrm{~B}, \mathrm{C}, \mathrm{D}$ & $\begin{array}{l}\text { Ongoing contact, } \\
\text { Predated outbreak }\end{array}$ \\
\hline $\mathrm{B}^{*}$ & $7 / 7$ & $15 / 8$ & $\mathrm{~A}, \mathrm{E}$ & $\begin{array}{l}\text { Ongoing contact, } \\
\text { Predated outbreak }\end{array}$ \\
\hline$C^{*}$ & $14 / 7$ & $15 / 8$ & A, D & $\begin{array}{l}\text { Ongoing contact, } \\
\text { Predated outbreak }\end{array}$ \\
\hline D & $25 / 7$ & $16 / 8$ & $\mathrm{~A}, \mathrm{C}$ & $20-29 / 7$ \\
\hline E & $25 / 7$ & Not available & $\mathrm{B}, \mathrm{F}$ & No information \\
\hline $\mathrm{F}^{*}$ & $25 / 8$ & $19 / 8$ & $\vec{E}$ & $25 / 7$ \\
\hline
\end{tabular}

* Members of same household

had sexual contact with both Patients A and C between 20 and 29 July.

Patient F, who lived with Patients A, B, and C, developed symptoms during the last week of August. A stool sample had been taken on 19 August while asymptomatic, because of his non-sexual exposure to other members of the household. This stool contained $G$. lamblia cysts. Subsequent investigation revealed that Patient $F$ had had sexual relations one month earlier with Patient E, who was also a sexual partner of Patient B. Patient E was not available for examination. However, he had been given 'antibiotics' for a diarrhoeal illness that began in the last week of July.

On re-interview, Patients $\mathrm{A}, \mathrm{C}, \mathrm{D}$, and $\mathrm{F}$ recalled oral-anal contact with other infected members of this group.

\section{Comment}

At least one stool from Patients A, B, C, and D was examined and found not to contain salmonella or shigella species.

Three other male residents of this household who had not had intercourse with any of Patients $A$ to $F$ were asymptomatic, and declined examination.

\section{Discussion}

The available data suggest but do not prove that $G$. lamblia infection was transmitted by the faecal-oral route during sexual relations in this group of homosexual men. A possible chain of transmission is shown in the Figure. Information derived from Patients $C, D$, and $F$ suggests an incubation period of between five days and four weeks after exposure.

Other reports of the transmission of parasitic diseases by sexual contact are available. G. lamblia proctitis has been diagnosed at a clinic for venereal diseases in a male patient who was thought to be

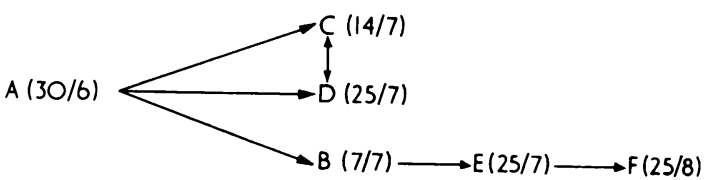

Figure Possible chain of transmission of $\mathrm{G}$. lamblia with dates of onset of diarrhoea

homosexual (Kacker, 1973), while Belding (1952) reports without comment that two-thirds of adult cases of $G$. lamblia occur in males. A patient with combined infection with $G$. lamblia and Enterobius vermicularis, who subsequently was found to have G. lamblia, E. nana, I. butschlii, and Dientamoeba fragilis infection, with possible relationship to homosexual contact has been commented upon (Abrahm, 1972; Lynch, 1972; Shookhoff, 1972). Patient A had I. butschlii and E. nana cysts as well as G. lamblia in his initial stool. Amoebiasis of the penis and cervix have been reported (Purpon et al., 1967; Cohen, 1973), as has threadworm infection among homosexual men (Waugh, 1972). We have recently observed a case of amoebic liver abscess in an urban homosexual male with no other obvious mode of contact.

The cluster of $G$. lamblia infections described here may have been transmitted by homosexual contact, and suggests that this and other parasitic diseases should be considered in homosexual patients presenting with diarrhoeal illness.

The authors acknowledge the contribution of $\mathrm{Dr}$ Frank P. Brancato, Ms Margaret Bohlander, and Ms Patricia Kubota in the identification of $G$. lamblia cysts in clinical specimens, and in providing data on previous isolations of $G$. lamblia at the USPHS hospital, Seattle.

\section{References}

Abrahm, P. M. (1972). Snakes in the grass or, the worm turns on. Journal of the American Medical Association, 221, 917.

Belding, K. L. (1952). Textbook of Clinical Parasitology, 2nd edition, p. 147. Appleton-Century-Crofts: New York.

Brodsky, R. E., Spencer, H. C., and Schultz, M. G. (1974). Giardiasis in American travelers to the Soviet Union. Journal of Infectious Diseases, 130, 319-323.

Cohen, C. (1973). Three cases of amoebiasis of the cervix uteri. Journal of Obstetrics and Gynaecology of the British Commonwealth, 80, 476-479.

Kacker, P. P. (1973). A case of Giardia lamblia presenting in a VD clinic. British Journal of Venereal Diseases, 49, 318-319.

Lynch, V. de P. (1972). Parasite transmission. Journal of the American Medical Association, 222, 1309-1310.

Moore, G. T., Cross, W. M., McGuire, D., Mollohan, C. S., Gleason, N. N., Healy, G. R., and Newton, L. H. (1969). Epidemic giardiasis at a ski resort. New England Journal of Medicine, 281, 402-407.

Purpon, I., Jimenez, D., and Engelking, R. L. (1967). Amebiasis of the penis. Journal of Urology, 98, 372-374.

Shookhoff, H. B. (1972). Parasite transmission. Journal of the American Medical Association, 222, 1310.

Waugh, M. A. (1972). Threadworm infestation in homosexuals. Transactions of the St. John's Hospital Dermatological Society, 58 , 224-225. 